\title{
Thermo-Mechanical Modelling of Bearing Chambers of a High-Speed Starter/Generator
}

\author{
Antonino La Rocca \\ University of Nottingham \\ Faculty of Engineering \\ Nottingham, United Kingdom \\ A.larocca@nottingham.ac.uk \\ Carol N. Eastwick \\ University of Nottingham \\ Faculty of Engineering \\ Nottingham, United Kingdom \\ Carol.Eastwick@nottingham.ac.uk
}

\author{
Peter H. Connor \\ University of Nottingham \\ Faculty of Engineering \\ Nottingham, United Kingdom \\ Peter.Connor@nottingham.ac.uk \\ Stephen J. Pickering \\ University of Nottingham \\ Faculty of Engineering \\ Nottingham, United Kingdom \\ Stephen.Pickering@nottingham.ac.uk
}

\author{
Zeyuan Xu \\ University of Nottingham \\ Faculty of Engineering \\ Ningbo, China - Nottingham, UK \\ zeyuan.xu@nottingham.ac.uk \\ Christopher Gerada \\ University of Nottingham \\ Faculty of Engineering \\ Nottingham, United Kingdom \\ Christopher.Gerada@nottingham.ac.uk
}

\begin{abstract}
This paper describes the thermal-mechanical characterisation methodology for the bearing chambers of a high-speed $(32,000 \mathrm{rpm})$ electrical starter/generator [1]; presenting a low cost analysis approach and design guideline for future machines. The methodology includes the estimation of the friction losses, overall thermal properties, bearing contact resistances and heat transfer coefficients. An analysis of the heat paths within the chambers, as well as within the whole rotor was carried out, allowing to quantify the heat extracted by the lubricant. The model was developed as part of the thermalmechanical design of a specific starter/generator but the modelling approach presented within this paper is applicable to any high speed application
\end{abstract}

Keywords- Thermo-mechanical Modelling, Bearings, HighSpeed, Thermal Network, Simulink, LPTN.

\section{INTRODUCTION}

The demand for high-speed electrical machines is steadily growing, due to the higher efficiencies and power densities they can achieve. High-speed machines are found in several applications, such as aerospace, automotive, power generation, tooling and energy storage [2]. However, increasing the rotational speed of electrical machines requires significant specialist design input in order to achieve the high level of reliability required by the industrial sectors cited above.

Literature shows that one of the main reasons of machine failure are bearings [3]. The mechanical failure of bearings can be caused through mechanisms such as incorrect estimation of the loads during the design stage, lack of lubrication, overheating and so on. For this reason detailed analyses of the friction losses taking place and a more detailed understanding of the heat dissipation within the bearing are extremely important in such demanding high-speed applications. Studies conducted in the past focus either on localised analysis of the bearing only, without taking into account the interaction with nearby components or use an FEA approach to look at the mechanical aspects of the bearings. The thermal and fluid dynamics aspects are often not considered [4 - 7].

This paper assesses the mechanical loss-generating aspects, heat transfer and the fluid flow phenomena within the bearing chambers, as well as the other neighbouring rotating components. A description of the analytical models used to estimate the friction loss is presented; providing a full understanding of the nature of this power loss. A number of critical parameters were estimated and a thermal network of the whole rotor was developed adopting the lumped parameter thermal network (LPTN) method. The modelling approach adopted can therefore be applied to the majority of high-speed applications where detailed information regarding the thermomechanical behavior is required. Furthermore, the flexibility and the low computational cost of this method can make it preferable when compared to a numerical approach. Indeed the modelling of two-phase fluid interactions, especially within a very complex system requires a significantly high computation power.

\section{CASE ANALYSED}

The machine design taken into consideration employs two different types of bearings manufactured by SKF; a cylindrical roller bearing at the drive end and two paired angular contact ball bearings in a back-to-back configuration at the non-drive end, Table I shows the bearings specifications. The bearings are lubricated with an air/oil mixture. In order to prevent the oil from flooding into the machine rotating air-cavity or from leaking out of the machine, labyrinth seals were used. Additional components, such as locking nuts and spacers were also used to accurately locate the bearings and to apply a preload. As a result, the bearings are enclosed into chambers, as shown in Figure 1. Complex geometries and the presence of multiphase flow, rotation and thermal effects mean modelling bearing chambers is computationally highly demanding for numerical Computational Fluid Dynamics (CFD) analysis. For this reason a LPTN was developed in MatLab Simulink. The model was built to investigate the heat transfer phenomena within the bearing chambers, as well as to evaluate their overall thermal conductivity.

TABLE I: Bearings Specifications

\begin{tabular}{|l|l|l|l|l|}
\hline $\begin{array}{c}\text { Bearing } \\
\text { type }\end{array}$ & Model & $\begin{array}{c}\text { Inner } \\
\text { diameter }\end{array}$ & Width & Height \\
\hline $\begin{array}{l}\text { Cylindrical } \\
\text { roller }\end{array}$ & $\begin{array}{l}\text { N1008 } \\
\text { KPHA }\end{array}$ & $40 \mathrm{~mm}$ & $15 \mathrm{~mm}$ & $14 \mathrm{~mm}$ \\
\hline $\begin{array}{l}\text { Angular } \\
\text { contact }\end{array}$ & $\begin{array}{l}71906 \\
\text { CD }\end{array}$ & $30 \mathrm{~mm}$ & $9 \mathrm{~mm}$ & $8.5 \mathrm{~mm}$ \\
\hline
\end{tabular}




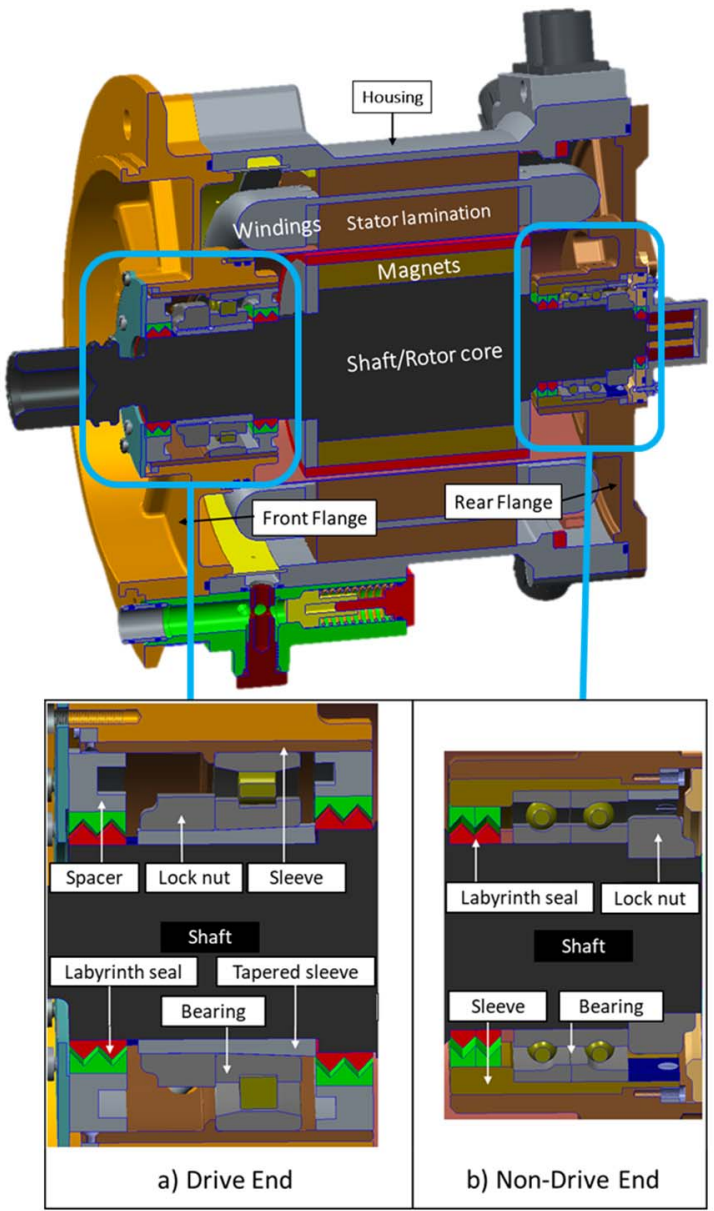

Figure 1: Bearing Chambers Design

\section{ANALYTICAL MODEL}

The development of a thermal network for both bearing chambers initially required the estimation of critical parameters such as the interface contact resistance between rotating elements and races, the heat transfer coefficient inside the chambers, the bearing friction loss and the overall material properties of the chamber. These are described in sections $A$ to $D$.

Before setting up the model the following assumptions were made:

- Heat transfer occurs mainly by convection and conduction. Radiation was neglected, due to the low temperature differences between the bearings and their surroundings.

- Due to the very tight interference fit, contact resistances for most of the components were not considered.

- Due to the thermal gradients expected, conductive heat transfer occurs along the radial direction only.

- Friction losses are evenly distributed between the outer and inner races.

- The heat transferred through the small air-gap between the inner and outer ring of the labyrinth seals occurs by conduction only.

\section{A. Thermal Resistance Rolling Elements/Racess}

The contact resistance between the bearing races and rotating elements cannot be evaluated by standard formulations. Generally the thermal contact resistance between the rotating elements and the races depends on the shape and size of the area in contact. The width of this area depends not only on the geometry of the bearing but also on the plastic deformation of the rotating elements due to applied loads, lubricant used and rotational speed; analytical and experimental studies have been reported in the literature that investigate how these factors affect the overall thermal resistance [8-11]. Based on these studies some typical values of conductance were used in the network built; Table II shows the value that were used.

TABLE II: thermal conductance between bearing races and rolling elements

\begin{tabular}{|c|c|c|}
\hline Bearing & Preload (N) & $\begin{array}{c}\text { Thermal Conductance } \\
\text { races/rolling elements (W/K) }\end{array}$ \\
\hline Roller bearing & 0 & 0.15 \\
\hline $\begin{array}{c}\text { Angular contact } \\
\text { bearing }\end{array}$ & 100 & 0.2 \\
\hline
\end{tabular}

\section{B. Convective Heat Transfer in Bearing Chambers}

Due to the complexity of the fluid flow expected inside the bearing chambers, the convective phenomena cannot be modelled using correlations available in textbooks. Due to rotation, the air/oil mixture is splashed over the internal surfaces of the chambers and the heat dissipated by convection can be significant. Analytical and experimental studies [12, 13] have attempted to weigh the impact of several factors such as chambers geometry, air flow rate from labyrinth seals, oil flow rate and rotational speed on the convection heat transfer. These studies led to an empirical correlation (Equation 1) for the determination of the heat transfer inside bearing chambers, taking into account all variables involved.

$$
N u=0.35 D_{h}^{1.46} \operatorname{Re}_{L}^{\prime 0.48} \operatorname{Re}_{F}^{\prime 0.32} \operatorname{Re}_{U}^{0.35}
$$

Where $D_{h}$ is the hydraulic diameter (m) of the chamber, $R e^{\prime}{ }_{L}$ is the Reynolds number accounting for the air flowing through the labyrinth seals into the chamber, $R e_{F}^{\prime}$ is the Reynolds number function of the oil flow rate used and finally $R e_{U}$ is the Reynolds number accounting for the effect of the rotation. A synthetic lubricating oil (BP-2389) was used with an inlet temperature of $120^{\circ} \mathrm{C}$, whilst air was at standard ambient temperature. Given that the oil flow rate expected was much larger than the air flow rate, it was assumed that the average temperature of the mixture was equal to the oil inlet temperature. This was used for the determination of the fluid properties used in Equation 1. Figure 2 shows the heat transfer coefficient obtained for this specific configuration; the order of magnitude of these results is in line with those obtained experimentally in [12]

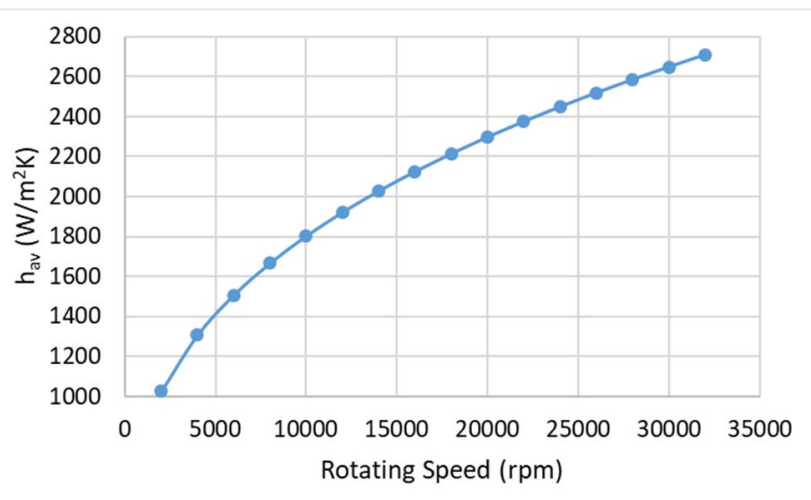

Figure 2: Heat transfer coefficients as function of rotating speed 


\section{Bearing Friction Loss}

Bearing losses are generated by the friction between the rotating elements and the races. This power loss is a function of several factors such as shaft speed, bearing type, lubricant and the loads applied. Several approaches are used to estimate the friction loss, from very simplistic [14] to more complex models where all the variables involved are accounted for. In this work two models are investigated; first Palmgren's model [15], and second the model provided by the manufacturer (SKF) [16].

In the Palmgren's model, presented in Equation 2, the total friction torque $\mathrm{M}_{\mathrm{F}}$ is the sum of the viscous friction torque $\mathrm{M}_{0}$ depending on the lubricant physical properties and flow rate, and the frictional torque component $\mathrm{M}_{1}$ function of the load applied to the bearing.

$$
M_{F}=M_{0}+M_{1}
$$

The SKF model takes also into account the oil levels and the oil properties variation due to temperature change; these are shown in Equation 3.

$$
M_{F}=\phi_{i s h} \phi_{r s} M_{r r}+M_{s l}+M_{\text {seal }}+M_{\text {drag }}
$$

The first two terms $M_{r r}$ and $M_{s l}$, are the rolling frictional moment and sliding frictional moment respectively, and are comparable to $M_{0}$ and $M_{1}$ of the Palmgren's model; however, the following additional terms are included:

- $\quad M_{\text {seal }}-$ The Sealing Frictional Moment takes into account the friction generated by seals if used. This term is excluded in this work as the featured bearings do not have seals.

- $\quad M_{d r a g}-$ The Drag Frictional Moment term is only used if bearings are partially submerged in oil so it is also excluded.

- $\phi_{i s h}-$ The Inlet Shear Heating Reduction Factor takes into account the viscosity reduction of the lubricant due to shear; this reduces the film thickness and rolling friction.

- $\phi_{r s}-$ The Kinematic Replenishment/Starvation Reduction Factor takes into account the "kinematic starvation" effect occurring at high speeds when the lubricant may not have sufficient time to replenish the raceways; the kinematic starvation reduces the thickness of the hydrodynamic film and hence the rolling friction.

All equations and coefficients are tabled for each bearing model in the SKF manual [16].

The SKF model can include additional terms taking into account the oil levels and variation in its properties due to temperature change. Table III shows the friction loss calculated at $32,000 \mathrm{rpm}$ using these three different approaches; it can be seen that the additional terms to the SKF model can make a significant difference especially at lower lubricant temperatures.

Table III: Bearing Friction Loss in W at 32,000 rpm

\begin{tabular}{|c|c|c|c|c|}
\hline \multirow{3}{*}{ Model } & \multicolumn{2}{|l|}{$\begin{array}{l}\text { Angular } \\
\text { bearings }\end{array}$} & contact & \multicolumn{2}{c|}{ Cylindrical roller bearing } \\
\cline { 2 - 5 } & $40{ }^{\circ} \mathrm{C}$ & $100{ }^{\circ} \mathrm{C}$ & $40{ }^{\circ} \mathrm{C}$ & $100{ }^{\circ} \mathrm{C}$ \\
\hline
\end{tabular}

\begin{tabular}{|l|c|c|c|c|}
\hline Palmgren's & 414 & 170 & 393 & 163 \\
\hline $\begin{array}{l}\text { SKF (without } \\
\text { additional } \\
\text { terms) }\end{array}$ & 433 & 220 & 347 & 151 \\
\hline $\begin{array}{l}\text { SKF(with } \\
\text { additional } \\
\text { terms) }\end{array}$ & 232 & 180 & 123 & 101 \\
\hline
\end{tabular}

\section{Overall Chamber Material Properties}

Averaged values of fluid density and heat capacity based on the chamber components were evaluated using Equations 4 and 5; where $\bar{\rho}$ is the average density in $\mathrm{kg} / \mathrm{m}^{3}, m$ and $V$ are the mass and the volume of each component inside the bearing chamber expressed in $\mathrm{kg}$ and $\mathrm{m}^{3}$ respectively and $\overline{C p}$ is the average heat capacity of the bearing chamber expressed in $\mathrm{J} / \mathrm{kgK}$. The dependency of these two values on the temperature was neglected.

$$
\begin{gathered}
\bar{\rho}=\frac{\Sigma m_{x}}{\Sigma V_{x}} \\
\overline{C p}=\frac{\Sigma C p_{x} m_{x}}{\Sigma m_{x}}
\end{gathered}
$$

The overall chamber thermal conductivity was estimated by building a thermal network of the chamber itself, which included the conductive path across which a known temperature gradient was applied. From this the power (heat flow) can be measured and therefore the resistance can be identified. The approach used to determine of the overall chamber thermal conductivity will be described in the following paragraph.

\section{THERMAL NETWORK}

The complete thermal network was developed within MatLab Simulink and this included all the rotor components and its conceptual schematic is shown in Figure 3. As the machine design considered has an oil-cooled flooded stator region, which is physically separated from the rotor region, a constant temperature was assumed at the outer boundary beyond the airgap.

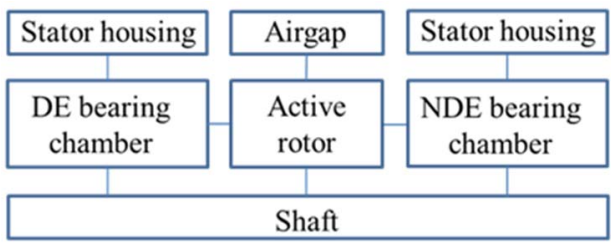

Figure 3: Schematic Full Rotor Thermal Network

Drive End (DE), Non Drive End (NDE) and active rotor network were developed separately and later combined together.

Due to the complexity of the full thermal network of the entire bearing chambers, details of the thermal resistances (both conductive and convective) used for the bearing only are shown in Figure 4. Conductive resistances between nodes 12, 2-3, 3-5 and 5-6 represent the resistances of the races and the contact resistances between races and rotating elements, convective resistances between nodes 2-4, 3-4 and 4-5 are used to model the convective heat transfer of races and rotating elements. The same approach was used for the angular contact bearings. 
The cooling effect given by the lubricating oil was modelled by including a fluid thermal resistance between nodes 4 and 7, evaluated using Equation 6

$$
R_{\text {flow }}=\frac{1}{\rho C_{p} \dot{v}}
$$

Where $\rho$ and $\dot{v}$ are the fluid density and volumetric flow rate respectively.

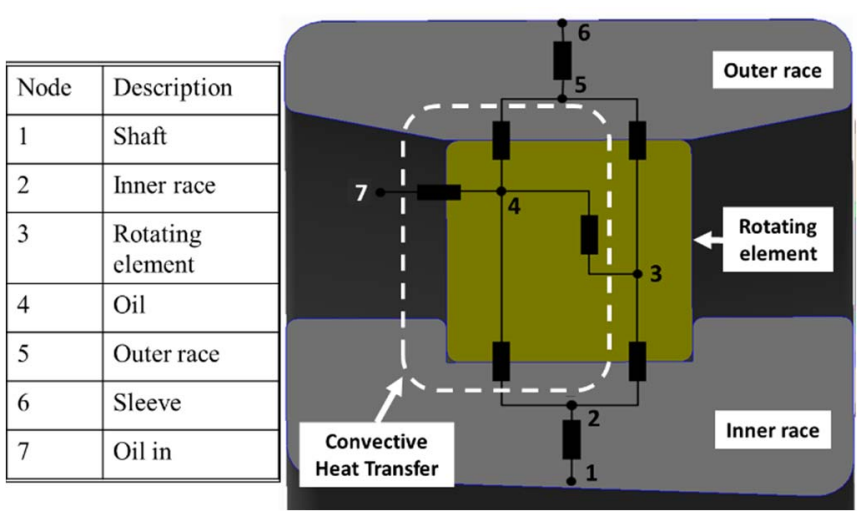

Figure 4: Bearing thermal resistances showing node locations

The bearing thermal network was developed using MatLab-Simulink thermal module. As literature shows, this modelling tool is also used for thermal analysis of electrical machines $[17,18]$. The following steps were followed for the development of the full thermal network:

- Bearing chamber conductive path: a network including conductive resistances only was developed to estimate the overall thermal conductivity of both chambers; these values can then be implemented into larger CFD models where bearings are simplified into modelled bulk solid regions. Figure 5 shows the conductive thermal network of the non-drive end bearing chamber built using MatLab.

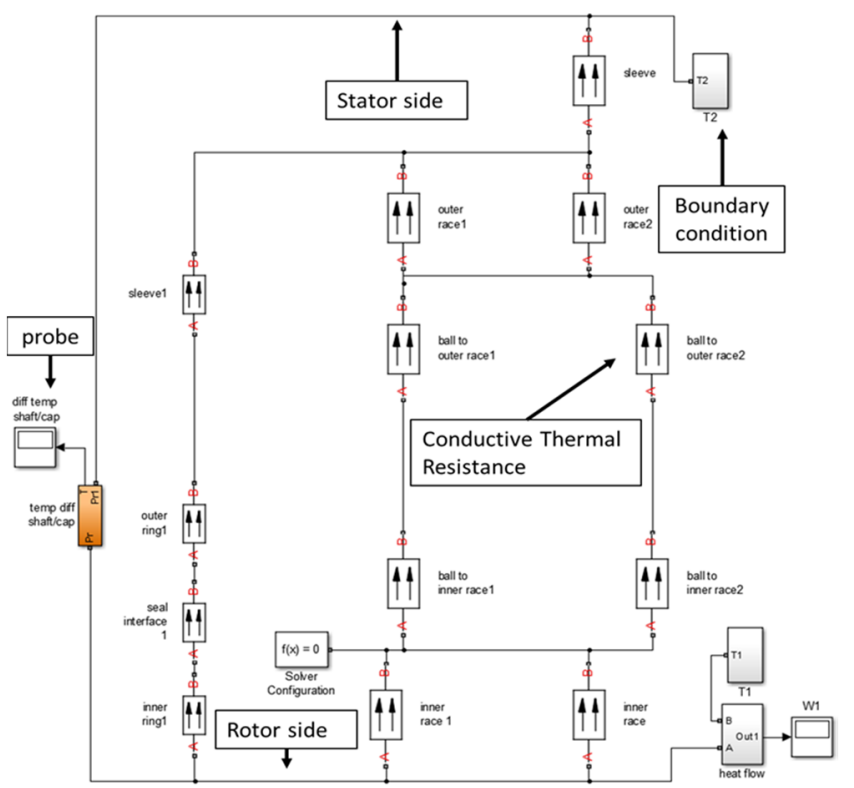

Figure 5: Bearing Chamber Conductive Path

The determination of the overall chamber thermal conductivity was performed by applying a temperature gradient $\Delta \mathrm{T}$ between the outer and inner diameter of the chamber, the temperature difference induces a heat flux $\dot{Q}$ allowing the overall conductive thermal resistance to be calculated by using Equation 7; assuming the chamber as hollow cylinder which dimensions are known Equation 8 could be finally used giving the value of the overall chamber thermal conductivity.

$$
\begin{gathered}
R_{\text {cond }}=\frac{l}{k A} \\
\dot{Q}=\frac{\Delta T}{R_{\text {cond }}}
\end{gathered}
$$

- $\quad$ Full bearing chamber modelling: convective thermal resistances were included in the previous network to account for convection heat transfer. Convection heat transfer was assumed for all chamber internal surfaces which were expected to be wet by oil. By including the convective thermal resistances the network shown in Figure 5 was updated to the following network shown in Figure 6.

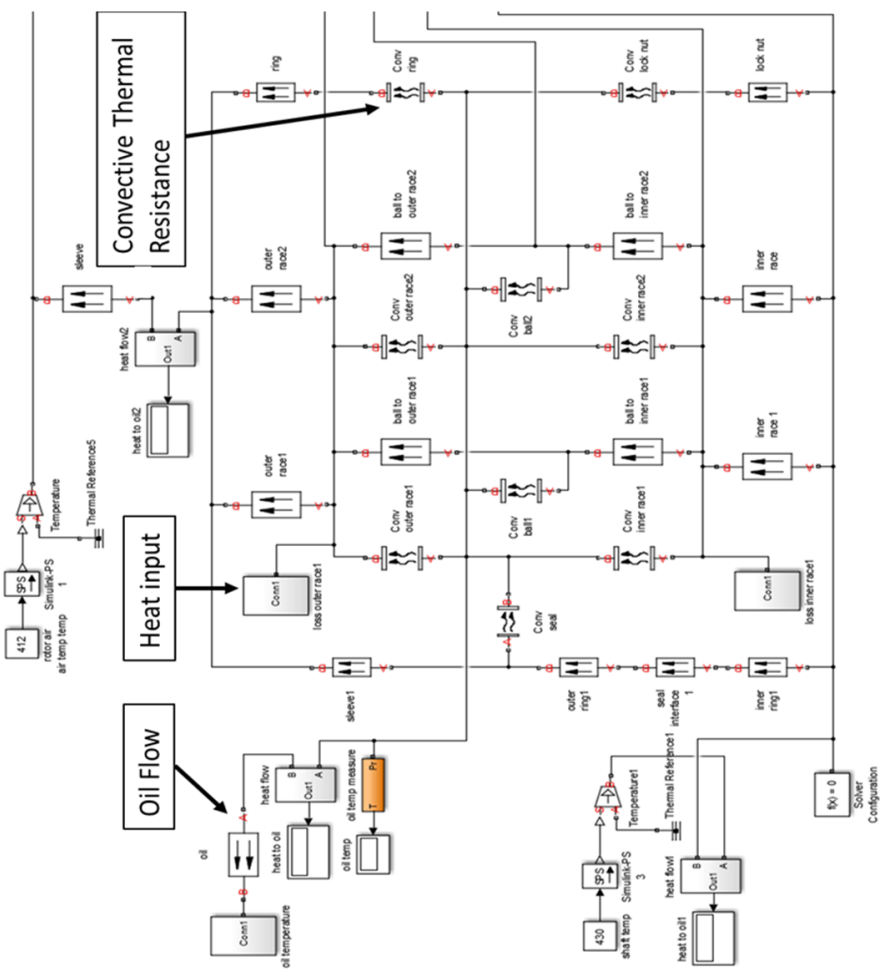

Figure 6: Chamber full thermal network

- Active Rotor modelling: Combining the two chamber networks by extending the circuit to the entire rotor can provide a better understanding of the heat transfer within the rotor components. For this reason a network including shaft, rotor core, magnets and banding sleeve was built. 


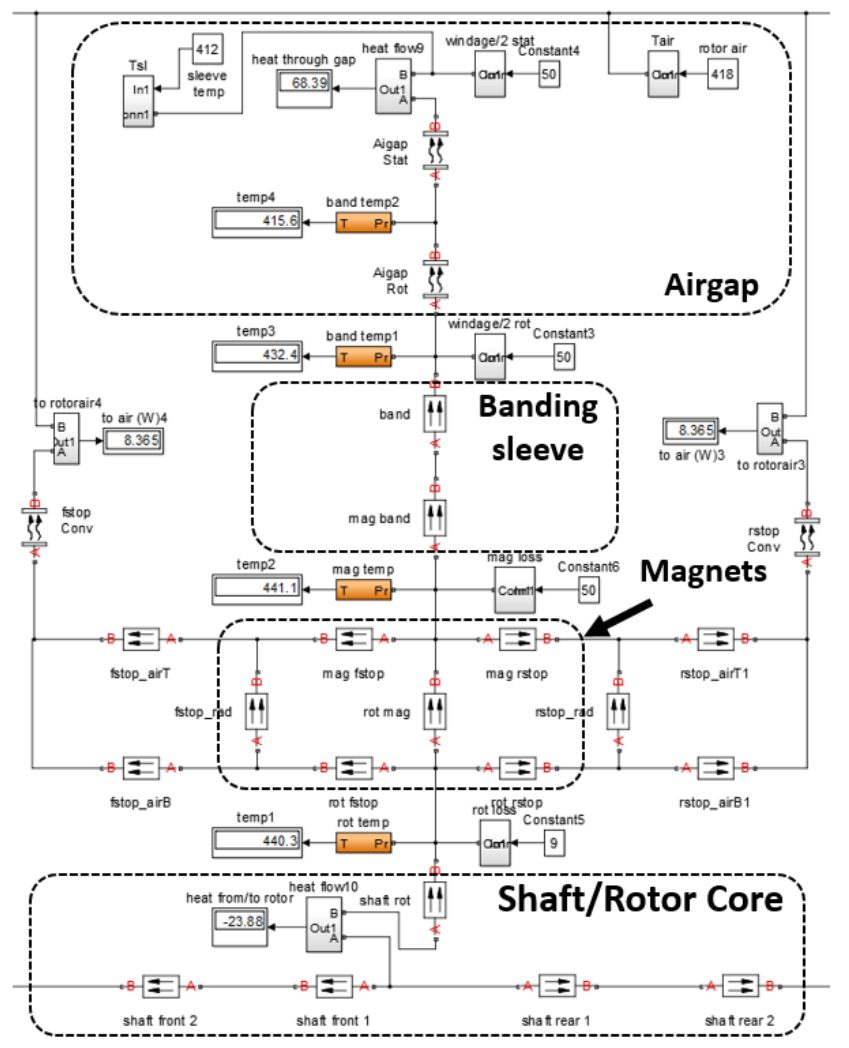

Figure 7: Active Rotor Thermal Network

For a better understanding Figure 8 shows a simplified schematic (and only half rotor) of the network presented above.

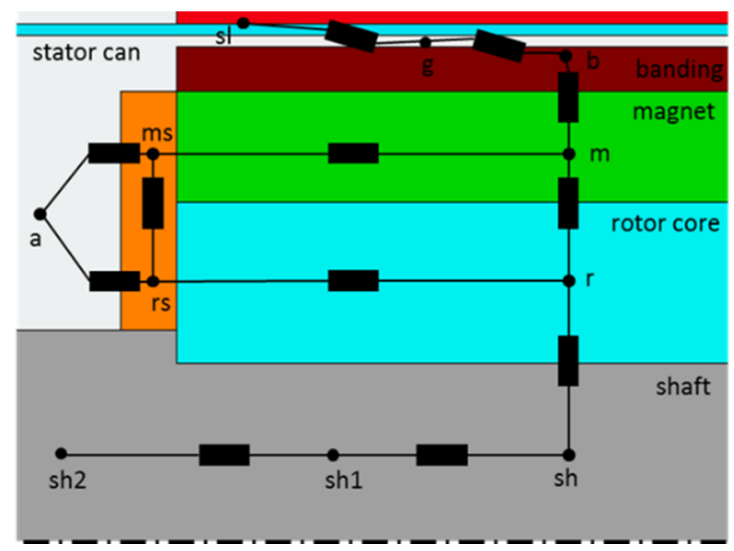

Figure 8: Schematic Active Rotor Thermal Network

The constructed network has identified the temperature distribution within the rotor, the amount of heat dissipated into the lubricating oil and how the heat is dissipated within the rotor region; this data, shown in Table IV.

\begin{tabular}{|l|c|}
\hline Table IV: Heat Removed by the Lubricant at 32,000 rpm \\
\hline Chamber & $\begin{array}{l}\text { \% of heat removed by air/oil } \\
\text { mixture (W) }\end{array}$ \\
\hline Drive End & 30 \\
\hline Non-Drive End & 50 \\
\hline
\end{tabular}

\section{EXPERIMENTAL RESULTS}

Experimental tests were undertaken to validate the analytical predictions made. The starter/generator was tested using a high speed rig with maximum speed rating of 35,000 $\mathrm{rpm}$. The high speed rig consists of a drive motor (an induction machine) connected to the machine under test through a gearbox and using a connection with a splined coupling. Figure 10 shows a schematic of the test rig, the starter/generator is attached to the test bed using a flanged connection.

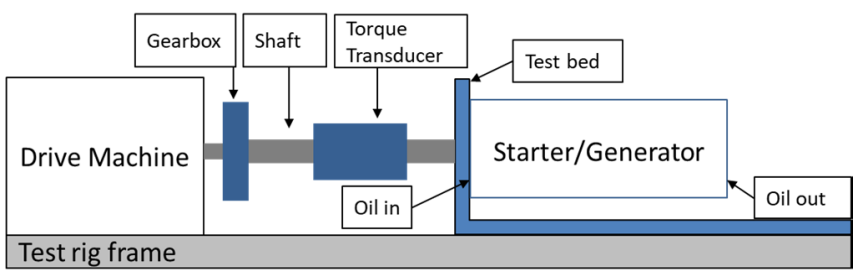

Figure 10: Schematic of Test Rig

Torque and speed measurements were required to identify the mechanical losses at different operating speeds; these data can be then compared to the windage and bearing losses previously estimated.

A torque transducer, ET-1303 by Torquemeters, was used; this is connected to the starter/generator using a flexible coupling and a splined connection.

Throughout testing torque measurements were taken when steady-state condition of the torque was achieved.

A no-load test was carried out in a sufficiently wide speed range $(1,000-20,000 \mathrm{rpm})$ for validating the analytical predictions. The test consisted of driving the starter/generator at different operating speeds by using the drive motor and leaving the test machine terminals in open circuit condition; the torque measured allows the calculation of the total power loss given by mechanical and electromagnetic contributes. Although a good match between experimental and analytical data is shown, it is important to notice that the torque transducer used had an accuracy of $0.12 \%$ at the full scale ( $\pm 300 \mathrm{Nm}$ ), meaning $\pm 0.36 \mathrm{Nm}$. Table $\mathrm{V}$ shows the total power loss calculated based on the torque measured and the loss components estimated. Whilst all mechanical losses were predicted analytically by the author, the electromagnetic component was numerically estimated by electrical team members involved in the project. As can be seen a better agreement between the total estimated loss and the experimental measurements is achieved at operating speeds above $10,000 \mathrm{rpm}$ where the maximum difference achieved is $12 \%$ as shown in Table 6 ; as machine designed is targeted for high speed application, predictions can be considered satisfactory. Figure 11 shows a comparison of the trend of the total power loss measured and estimated.

\begin{tabular}{|c|c|c|c|c|}
\hline \multirow[b]{3}{*}{$\begin{array}{l}\text { Speed } \\
(\mathbf{r p m})\end{array}$} & \multicolumn{4}{|c|}{ Power Losses (W) } \\
\hline & \multirow{2}{*}{$\begin{array}{c}\text { Measured } \\
\text { Total } \\
\end{array}$} & \multicolumn{3}{|c|}{ Analytical Prediction } \\
\hline & & $\begin{array}{c}\text { Electro- } \\
\text { magnetic }\end{array}$ & Mechanical & $\%$ diff. \\
\hline 1,000 & 13 & 6 & 7 & 46 \\
\hline 2,000 & 31 & 15 & 20 & 36 \\
\hline 3,000 & 50 & 25 & 35 & 30 \\
\hline 4,000 & 68 & 38 & 53 & 22 \\
\hline 5,000 & 93 & 52 & 74 & 21 \\
\hline 6,000 & 118 & 67 & 96 & 18 \\
\hline
\end{tabular}




\begin{tabular}{|c|c|c|c|c|}
\hline 7,000 & 141 & 84 & 121 & 14 \\
\hline 8,000 & 174 & 102 & 147 & 16 \\
\hline 9,000 & 210 & 122 & 175 & 17 \\
\hline 10,000 & 250 & 143 & 206 & 18 \\
\hline 11,000 & 240 & 165 & 238 & 1 \\
\hline 12,000 & 268 & 188 & 272 & 2 \\
\hline 13,000 & 315 & 212 & 308 & 2 \\
\hline 14,000 & 385 & 238 & 346 & 10 \\
\hline 15,000 & 422 & 265 & 386 & 8 \\
\hline 16,000 & 483 & 293 & 428 & 12 \\
\hline 17,000 & 508 & 322 & 471 & 7 \\
\hline 18,000 & 551 & 353 & 517 & 6 \\
\hline 19,000 & 608 & 384 & 564 & 7 \\
\hline 20,000 & 652 & 417 & 613 & 6 \\
\hline
\end{tabular}

This modelling approach can therefore provides detailed information regarding the dissipation of rotor losses within the rotor, including electromagnetic and mechanical. It can also be used to identify the optimal lubricant flow rate required, which would still guarantee the right level of lubrication and cooling without significantly increase the friction loss.

The empirical formulation used to estimate the heat transfer coefficient within the chamber can allow identifying the appropriate oil-air ratio to maximise the heat dissipation without compromising the lubrication effect.

The advantage of such a model is that the same methodology can be applied to other rotor designs without significantly modifying aspects of the existing network, other than the material properties and dimensions.

\section{REFERENCES}

[1] A. La Rocca et al., "Thermal management of a high speed permanent magnet machine for an aeroengine," 2016 XXII International Conference on Electrical Machines (ICEM), Lausanne, 2016, pp. 2732-2737.

The test was carried out using lubricating oil at a constant inlet temperature of $55^{\circ} \mathrm{C}$ so it follows that bearings friction losses were calculated at that temperature. Each operating point was run until no variations were identified in the torque readings.

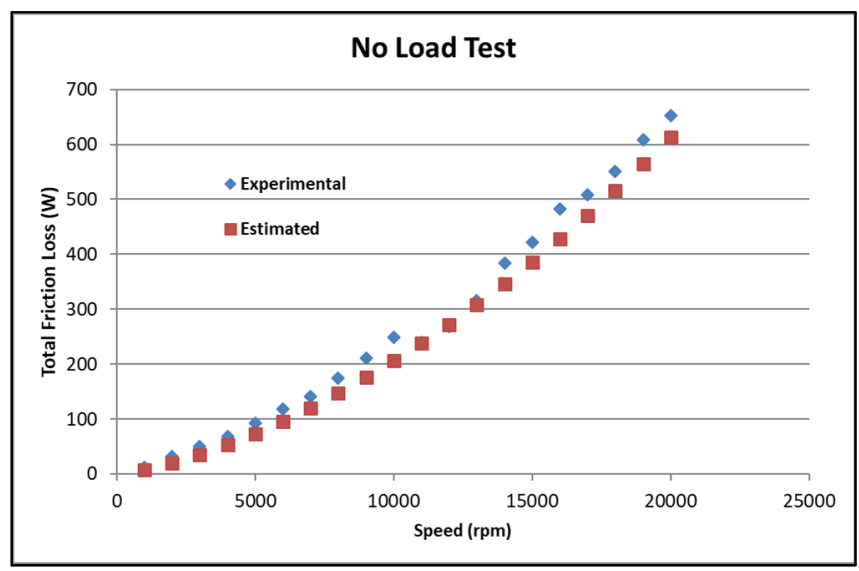

[2] D. Gerada, A. Mebarki, N. L. Brown, C. Gerada, A. Cavagnino and A. Boglietti, "High-Speed Electrical Machines: Technologies, Trends, and Developments," in IEEE Transactions on Industrial Electronics, vol. 61 , no. 6 , pp. 2946-2959, June 2014

[3] S. Nandi, H. A. Toliyat, and X. Li, "Condition monitoring and fault diagnosis of electrical motors - a review," IEEE Transactions on Energy Conversion, vol. 20, no. 4, pp. 719-729, 2005.A. B. Author, C. D. Author. "Title of the article", The Journal, volume, pp. 110120, (2000).

[4] E. Uhlmann, J. Hu, Thermal Modelling of a High Speed Motor Spindle, In Procedia CIRP, Volume 1, 2012, Pages 313-318, ISSN 2212-8271

[5] MA Chi, MEI Xuesong, YANG Jun, et al. Thermal characteristics analysis and experimental study on the high-speed spindle system. International Journal of Advanced Manufacturing Technology, 2015, 79(1-4): 469-489.

[6] Yu Chen, Yu Sun, Wuxue Ding, Thermo-mechanical Coupling Model and Dynamical Characteristics of Press Actuator, In Procedia Engineering, Volume 81, 2014, Pages 1657-1662, ISSN 1877-7058

[7] Zhenhuan Ye, Liqin Wang, Guanci Chen, Di Tang, Analysis of thermo-mechanical coupling of high-speed angular-contact ball bearings, Advances in Mechanical Engineering, Volume 9, 2017

[8] Bossmanns, B. and J.F. Tu, A thermal model for high speed motorized spindles. International Journal of Machine Tools and Manufacture, 1999. 39(9): p. 1345-1366.

Figure 9: No-Load Losses Trend

\section{CONCLUSIONS}

The lumped parameter network method used for the thermal modelling of electrical machines allows quick analyses of the heat transfer problems with relatively low computational cost. Complex geometries and phenomena can be reduced to relatively simple networks of thermal resistances that are simple to set up. The high speed of calculation makes this method a suitable tool for the investigation of the thermal behaviour of existing machines or new designs.

A thermal network of the full rotor of a high-speed electrical machine was developed; particular attention was focused on estimating the critical physical parameters of the complex bearing chamber structures, as well as to the fluid dynamic aspects of the lubrication cooling. This has provided detailed information regarding the temperature distribution and the heat paths within the rotor. This approach can therefore be used to estimate the rate of heat dissipated into the lubricating and the rate of heat which is transferred to the other machine components.

[9] Nakajima, K., Thermal Contact Resistance Between Balls and Rings of a Bearing Under Axial, Radial and Combined Loads. Journal of Thermophysics and Heat Transfer, 1998. 9: p. 88-95.

[10] Takeuchi, R., Eby, A., Blake, A., Demsky, M., Dickey, T. Influence of Oil Lubrication on Spacecraft Bearing Thermal Conductance. in 38th Aerospace Mechanisms Symposium. 2006. Langley Research Center.

[11] Takeuchi, R., Frantz, P., Hilton, M. Observations of Spacecraft Bearing Lubricant Redistribution Based on Thermal Conductance Measurements. in 42nd Aerospace Mechanisms Symposium. 2014. NASA Goddard Space Flight Center.

[12] Glahn, A., Wittig, S., Two-Phase Air/Oil Flow in Aero-Engine Bearing Chambers - Assessment of an Analytical Prediction Method for the Internal Wall Heat Transfer. International Journal of Rotating Machinery, 1999. 5(155-165).

[13] Busam, S., Glahn, A., Wittig, S., Internal Bearing Chamber Wall Heat Transfer as a Function of Operating Conditions and Chamber Geometry. Journal of Engineering for Gas Turbines and Power, 2000. 122(2): p. 314-320.

[14] Pyrhonen, J., T. Jokinen, V. Hrabovcová, Design of Rotating Electrical Machines2008, Chichester, West Sussex, United Kingdom: Wiley.

[15] Brändlein, J., Eschmann, P,. Hasbargen, L., Weigand, K., Ball and Roller Bearings: Theory, Design and Application, 3rd Edition1999: Wiley.

[16] SKF, Rolling Bearings, 2012. 
[17] Fakhfakh, M.A., et al., Thermal Analysis of a Permanent Magnet Synchronous Motor for Electric Vehicles. Journal of Asian Electric Vehicles, 2008. 6(2): p. 1145-1151.
[18] Demetriades, G.D., et al., A Real-Time Thermal Model of a PermanentMagnet Synchronous Motor. Power Electronics, IEEE Transactions on, 2010. 25(2): p. 463-47 